\title{
Impact of Online Customer Relationship Management (OCRM) Upon Customer's Satisfaction in Post Covid-19 Scenario. A Case Analysis of Standard Chartered Bank Pakistan
}

\author{
Dr. ALI MUHAMMAD \\ PhD UK, Postdoc Canada \\ Asst. Professor, Institute of Management Studies, University of Peshawar. \\ Email: Alimohmand@uop.edu.pk
}

\author{
AIZA HUSSAIN RANA \\ Assistant Professor, Department of Management Sciences, \\ Lahore Garisson University, Lahore. \\ Email: Aizahussainrana@lgu.edu.pk
}

\begin{abstract}
This study investigates the impacts of online Customer Relationship Management (OCRM) on the level of customer satisfaction and retention in the Pakistani Banking industry. Recent past has witnessed workplace shift toward workspace especially in post-Covid scenario. Covid-19 pandemic have pushed banks in developed countries to move its day-to-day operations to purely online, following which Pakistani banks are also going global yet customer satisfaction and retention still remains a dilemma. A case analysis of Standard Chartered Bank has been chosen in the relatively troubled state of Khyber Pakhtunkhwa. This research is an attempt to empirically highlight the importance of OCRM for the banks' overall growth and performance. A causal relation between customers' satisfaction and retention with that of OCRM is examined through various pathways. Primary data from 100 staff members from 18 branches of the bank were collected using convenience sampling and questionnaire-based survey in summer 2020. Six hypotheses were developed and testing using regression analysis. The results suggest that OCRM bears direct positive relation with customer satisfaction and retention with moderating effects of perceived value, price and switching cost. Through customized services, banks should rigorously pursue online services and treat this pandemic an opportunity. Online services can be viable platform for positioning the banks' new offerings to customers. Important lessons and recommendations for banking industry are put forward. The paper concludes with limitations and contributions.
\end{abstract}

Keywords: Standard Chartered, Online CRM, customers, satisfaction, retention, banks, Covid-19.

\section{Introduction}

In circumstances where most of the companies face stiff completion and are confronted with continuous innovation, globalization, and quality control, it becomes difficult to maintain growth targets and retain market share. Visionary companies then adopt innovative strategies to retain their customers satisfied. Of the many strategies, CRM is one of the most effective tools to keep the customers intact and contented. It is a tool used by firms to interact and keep in contact with their customers thereby offering them more personalized services with respect to their rivals. Wong (2011) argues that enhancing customer acceptance for the brand and retaining a loyal customer base is often a distinguishing character for firms. The situation 
gets worse in the post-Covid scenario where workplace has been almost transformed into workspace and companies attract the customers, influencing their attitudes and behaviours through personified online interactions which have ultimate results of increased customer satisfaction and loyalty for the brand.

Li \& Wu (2007) also supports the point and argue that CRM has been adopted by many firms in wide range of industries and have been able to achieve the desired goals of increasing customer acceptance and retaining their customers. Banking sector around the world presents too little differences in terms of the products and services they offer to their clients relative to their rivals, however banks which are capable of establishing sound interaction and follow up with their customers. Online banking approach is one of the most widely used tools for keeping in touch with the customers and thereby maintains an edge over the rivals in the industry. Customer relationship management through online banking services and products has helped banks to personalize their relationship with customers, has increased responsiveness, ease of information and transaction to the customers (Mbama \& Ezepue, 2018).

The concept of electronic banking in Pakistan was first introduced in 1980s however due to security barriers and lack of technological requisites, the experiment was not very fruitful and resulted in a failure. Later on, some new growing banks stepped into the technology and today there are several banks in Pakistan who are positioning themselves through their online banking facilities. Electronic banking in its broader sense is defined as a process through which banks offer online information to the customers, online access is allowed to their accounts and where electronic transaction is encouraged using the internet banking or telephonic banking (Cronin, 2009).

It is only in the recent past triggered by Covid pandemic that banks have been pushed toward adopting online services. The concept of CRM through online banking products and services was slowly pursued by the Pakistani banking industry and some important players in the industry have already gained significant implication of the technique used (Khan, 2007). To assess the long-term viability of online CRM, this study therefore investigates the impacts of online CRM on the level of customer contentment in the Banking industry.

\section{Standard Chartered Bank Limited Pakistan}

Standard chartered bank is one of the top 20 companies at the FTSE 100 Index which uses the market capitilization for the synthesis of the index. The bank operates with an international setup around the world providing consumer and coorporate banking services and products to customers around the world. The bank is listed both at London stock exchange and Hong Kong stock exchange. The bank operates with almost 1700 branches in sevnteen countries around the world with much of its concentration in Asia which can be assertined from the fact that almost $90 \%$ of the profit of the bank comes from asian markets. The bank has more then 2800 employee from more than 150 nationalities around the globe and almost half of the workforce of the bank comprises of females.

In pakistan the bank operates with almost 56 branches in 11 cities around the country and has become a main player in the industry after it acquied the Union Bank. The acquistion of Union bank Limited by Standard chartered resulting in the largest FDI flow to the country. It is also the first Foreign bank in Pakistan which acquired the liscence of Islamci Banking window in Pakistan. The bank is Rated AAA in Pakistan industry which shows its short term credit worthiness and soundeness. Due to the current performance profile, Standard Chartered Bank has been chosen as a Case for this particular research.

\section{Research Aims \& Objectives}

The CRM online banking activities are designed to enhance the efficiency of their relationship management with customers. The online banking CRM strategy is found to have favourable results for companies operating in developed markets. Pakistani banks have also pursued the strategy and Standard Chartered 
Pakistan is one of the leading banks moving towards this trend esp after Covid-19 pandemic. The purpose of this study therefore is to examine the impact of online Customer Relationship Management on customers' satisfaction and retention within the banking industry with special reference to Standard Chartered Bank, being a premier bank. The main objectives are as follow:

- To examine the impacts of online CRM on factors affecting customer satisfaction in an atmosphere of Covid-19 in the banking industry.

- To find the relationship of Online CRM and degree of customers satisfaction by undertaking standard chartered bank Pakistan as a case analysis.

- To evaluate the impacts of customer satisfaction on the retention of the customers for standard chartered bank Pakistan.

- To find out the impacts of Online CRM on the customer retention for standard chartered bank Pakistan.

\section{Literature Review}

Workplace in Covid-19 era has been changed dramatically to workspace which tempts many companies to focus on customer satisfaction and retention. Mostert et al., (2009) reports that customer retention is the policy of the company to avoid their customer from falling to their competitors achieved through effective CRM. Almost half a century ago companies concentrated on their production and the motive was to make enough production to meet the demands of the customers, however with the advent of technology and global business the consumer preferences, production and purchasing behaviours of the customers have changed (Gil, 2011).

Buckinx et al., (2007) presents that customer relationship management is a cycle, it is an interactive process through which the company retains its customers using the information obtained regarding their customers. Ryals and Knox (2001) argues that with the help of CRM the company retain their customer by building strong personal relation with them, the service quality and the follow up of the process present important attributes to the customer relationship management process.

Ralph \& Merlin (2009) presented the same view commenting that the consumers were not much imprisoned in the dilemma of choosing products or services and there were few providers from where the customers could have fulfilled their needs, however with the passage of time the trend has changed. Chan \& Lam, (2009) reports that the internet and information technology has changed the basics for CRM, the customer retention and CRM has shifted to ECRM by the inclusion of internet in the process, this allows the company to provide high quality, instant and responsive services to their customers, customizing the products and services of the company based on the information of the customers for higher level of satisfaction and retention.

Essinger, (2008) argues that customer relationship management is one area where the companies have focused for developing long term profitable and trustworthy relationship with their clients and for the reason the customer relationship management is an important strategy pursued by the banks (Strawser \& Wiggins, 2008) to build long term relationship with their clients.

CRM is an idea for dealing with an organization's collaborations with clients, customers, and potential customers. It includes utilizing innovation to sort out, computerize, and synchronize business forms. The aim of CRM is to upgrade productivity, wage, and consumer loyalty. To achieve CRM, numerous associations use set of instruments, advances, and strategies to bolster the association with the client to improve business. In this way, CRM is an issue of overall business and process instead of a specialized one (Dowling, 2002). 
The criticalness of consumer loyalty can't be rejected while satisfied clients are similar to free publicizing for the organization. It is important to put the client at the focal point of the business as indicated by its methodologies, occasions and forms. Truth be told, it is less demanding and more productive to offer to present clients than to discover new ones. Associations are setting themselves methodologies to guarantee client maintenance, and changing their workers to be more clients-centered and administration arranged (Mohsan et al., 2011).

Ratten (2020) and Joseph et al., (2003) have reported that the demographics and the preferences of the customers are changing with the passage of time and the customers have entered into an era where they are very conscious about their busy schedule and their increased preferences for the quality and responsiveness of the services offered by the firm to their customers. Saha \& Zhao (2005) also comments that with the end of industrial era and the emergence of marketing era has drastically changed the needs and the preferences of the customers, the busy schedule, invent of technology, increased competition and the global markets has influenced the behaviours and the attitudes of the customers regarding their buying process and their interactions with the firm. Simkin \& Bagranoff, (2008) presents that organizations have shifted from consumers' centric instead of production centric by that it is stated that understanding of the needs and preferences of customers in a more professional way, routine interactions, responsiveness, feedback on their complaints and assuring quality of the services is much more important than the offerings itself.

Lee, (2011) argues that customer relationship management is an ongoing process through which the management plans to remain in contact with their, sales and marketing personals. After the outbreak of Covid-19, businesses have been forced to reach to customers through optimum use of technology thus the prospects for developing long term and loyal relationship with the customers are increased (Ratten, 2020). In a recent thread, Nagel (2020) highlights the digital transformation of work in Covid-19 era, where customer satisfaction has received increased attention. Conin, (2009) also supports the view that customer relationship management is the process through which company finds and attract new customers, retain and nurture the existing customers of the company thereby reducing the marketing and administrative costs in doing so. Lombard, (2011) argues that customer relationship managent consist of customer interface departemnt as well as other such departments that intends to focus on their customers and retains a profitable and loyal customer base for the company.

Williams \& Spaul, (2008) has presented that the customer purchase is a mix of expectation regarding the offering of the company and the customer evaluates the purchase from the company on the basis of these predetermined expectation regarding the products and the services, expectation fulfilment leads to a higher level of satisfaction for the customers and a failure may lead to low acceptance for the brand. Gao \& Owolabi (2008) argues that CRM through online banking channel is based on the fundamental motive of better understanding and approaching clients of the banks, it includes data warehouse, operations, call center, ecommerce, online marketing, customer services and online sales.

Ralph \& Merlin (2009) presents that customer relationship management has many important implications for the business and help the company increase its sales by attracting new customers, effective and objective based planning for target markets and brand positioning, enhance customer services, better decisions making and enhanced efficiency for the firm (Rigby et al., 2003).

Power and Associates (2009) argues that the use of customer relationship management strategy helps the company to find a forum where they can easily present their new offerings and innovative products to the customers and make it easy for the firm to target their customers for the new offerings.

Holland \& Westwood, (2010) reports that the use of information technology holds a key position for the successful planning and implementation of the customer relationship management, firm can create database of their customers, locate and interact with their clients. Tomiuk \& Pinsonneault (2001) comments that in the current business and market context there is very little difference among the offerings and the strategies 
of firms, what can place a company with distinction is their relationship management with their clients, low cost strategy which can trigger the buying stimulus of the customers and can build strong long term relation with the client is a key to success in the markets. Bilal (2008) argues that online banking customer relationship is beyond the trend of ecommerece as it moves to build strong long term relationship between the bank and its clienst, it is a usefull mean for information flow from bank to their cleints and feedback from clients to the bank.

Uppal \& Kaur (2008) comments that the effceincy of the online CRM system of the bank depends on the collection of data and converting it into intelligent information. Data can come within or outside the organziation and requires an effceint and effcetive coordination and integration of the different components of CRM such as the customer bio data, call centre data, sales force and customer database.

Li \& Wu, (2007) argues that service quality to the customers is a key factor that influences the level of satisfaction for the customers, a batter understanding of the needs of the customers and offering based on such analysis has more probability of accepatnce from the customers. The study analyzed a sample of 1400 different customer in banking industry in UK to evlaute the quality of online banking CRM and its impacts on satisfaction and retention, results supports the point that customer relationship managent plays an important role in enhancing the level of satisfaction and help companies retain their customers. Wong, (2011) also analyzed the factors which infleunce the level of satisfaction and their loyality with the company, the resulsts of the study suggest that the customers in online banking industry suggest that customer higly values the switching costs and for the reason they have very low intentions of switching the barnd.

Khaligh et al. (2012) has analyzed the the relationship between the CRM and customer satsifaction in the Irinain Telecom industry from a sample of 200 customers. The resulsts of the study suggests that high leve of management vision and the effceint policies which are flexaible and explecitely stated can help company achieve its goals with the online relationship with their customers. In an analysis at the Korean market for a company which offer more than 30,000 online products by Kim et al., (2003), 16 online shopping malls were investigated for the analysis. The resulsts suggest that top management vigilance, perceived value and switiching cost for customers in the online industry are important for infleuning the level of customer satisfaction and the their loyalty with the brand. Bohling et al. (2006) found that internaly and externally guided metrices, measurable revenue developemnt, measurable decrease in cost, enhanced customer perception and customer satisfaction and retention are some of the key elemnt which can infleunce the Online CRM of the companies.

The literature discussed above presents that for many companies, customer satisfcation and retention have become pivotal especially after Covid-19 outbreak. The enchanced level of comepetion and the globalization of international markets have left the companies with very little edge over its rivals and for the erason companies have looked fro new and innovative technaqiues through which they can offer a differnce to their customers. CRM stands for the complex relation of the company with their customers that is triggered at providing personal, authentic and customize services to the customers and retaining these customers through countinouse interactions. The use of Information technology has presented new horizons for the CRM and posess great potentioal for gaining a competetive edge for the company in markets.

\section{Hypothesis of the Study}

The study has the following assumption regarding the results from the analysis of the data of the study.

Hypothesis: 1: OCRM has positive impacts on level of customer satisfaction for online banking customer of standard chartered Pakistan

Hypothesis: 2: Perceived value has direct relationship with customer satisfaction for online banking customer of standard chartered Pakistan 
Hypothesis: 3: Perceived cost has an inverse relation with customer satisfaction for online banking customer of standard chartered Pakistan

Hypothesis: 4: Perceived switching cost has an inverse relationship on level of customer satisfaction for online banking customer of standard chartered Pakistan

Hypothesis: 5: CS has positive impacts on level of customer retention for online banking customer of standard chartered Pakistan

Hypothesis: 6: OCRM has positive impacts on level of customer Retention for online banking customer of standard chartered Pakistan

\section{Theoretical framework and Constructs}

Figure 1 of the research presents the Theoretical model for the relationship of the dependent explanatory and the Moderating Variables. There are two Paths for each of the relationship of Customer Satisfaction, Customer Retention and CRM Online Banking Services.

\section{Customer Satisfaction and CRM Online Banking Services}

Figure 1 of the research presents that there are two paths which depicts the relationship among OCRM and customer satisfaction.

- Path 1 in the model presents the direct impacts of CRM online banking services on the customers' satisfaction level.

- $\quad$ Path 2 presents the relationship between CRM and Satisfaction through the mediating effects of following three variables.

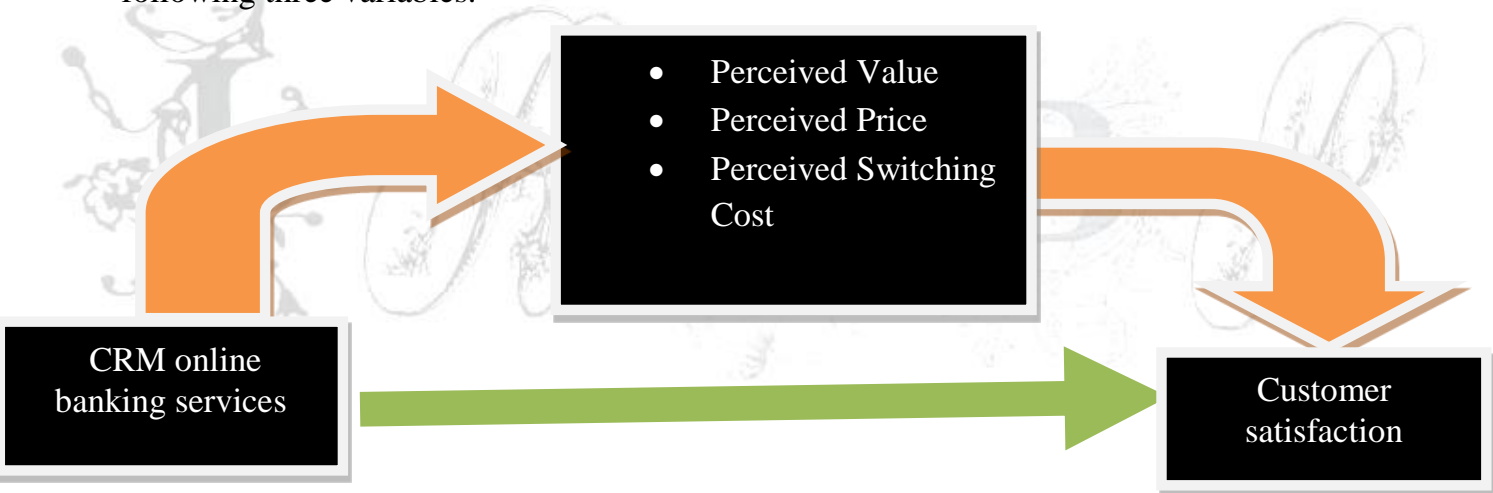

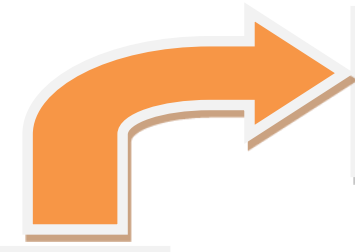

CRM online Banking

Independent variable

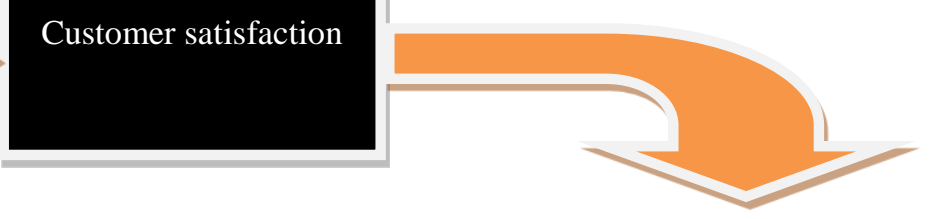

Customer Retention

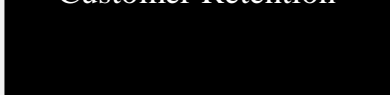

Dependent variable

Figure 1: Theoretical Model 


\section{Perceived Value}

Zeithaml (1988) has presented important aspects of the perceived value and suggests that the value evaluated by the customers comprises of four elements that includes low price for the value, value is all what the customer believe he needs in a product, in the their step quality of the offering is evaluated with the cost incurred by the customer and in the last step value is what customer get for what he has given. Tung, (2004) argues the same and supports that Value is the overall perceived utility in the product as perceived by the customer

\section{Perceived Price}

Perceived price is the customer analysis of the price of service or product offered by the competitors (Chen et al., 1994). Perceived price emphasis is on the comparison of the prices and evaluating whether the company is charging fairly or charging high as compared to its competitors. Zeithaml (1988) has also presented the fact that the perceived price is highly related with the overall perception of the value and the price plays an important role in determining the overall perception.

\section{Perceived Switching Cost}

Lai et al., (2011) refers to the cost in terms of time, value, monetary and psychological factors expected in the transition from one brand to another. Dick and Basu, (1994) argues that the perceived switching cost for the company includes the cost of searching new products and the cost and efforts required for making the new transaction. Schlesinger and Schulenburg, (1991) argues that the switching cost depends on the specification of the products and also on the context of the industry.

\section{CRM Online Banking Services and Customer Retention}

The relationship between the customer retention and the CRM services also follows two paths. In the first place the Figure shows a direct relationship between online banking CRM and customer retention. The second Path in the figure is through the mediating effects of customer satisfaction which influence the association amongst CRM online banking and Customer retention.

\section{Methodology}

\section{Population of the study}

The purpose of the study is to analyze the impact of Online banking CRM on the level of satisfaction and retention of customers in banking industry in Pakistan. The standard chartered bank of Pakistan is used for this purpose and the customers of the bank are surveyed for collecting the data related to the variables. The population of this research comprises of all the online banking customer of Standard Chartered bank of Pakistan

\section{Sample and sampling technique}

The sample for the study is collected from the population which includes the online banking customers of standard chartered bank Pakistan during 2020. The study used the following important steps in collecting the sample of the study. In the first step list of branches of Standard Chartered bank in KPK were acquired and this resulted in a sample of 18 different branches. There are four branches of standard chartered bank in Peshawar at different locations. These four branches out of the list were used for selecting the sample for the study. These branches were visited and based on convenience sampling technique, customers of the bank were interacted randomly in order to collect a list of online banking customers of the bank, obtained through personal networks. The study selected a final sample of 100 customers for the analysis. The final 
selected sample was used for the online survey purpose and the questionnaires of the study were mailed to these customers.

\section{Data Collection Procedure}

The study utilized both primary and secondary data for investigating the relation of online banking CRM and customer satisfaction. Secondary data used in the study was mainly collected from secondary sources such as books, book section, articles, research papers, thesis, draft papers, reports and other published content on the internet. The secondary data in the analysis was mainly used for the definitions and explanations of the different terms and concepts and the relationships. The secondary data was also used for presenting the findings and the analysis from the previous studies.

The primary data which was used for examining the link of online CRM with satisfaction and customer retention is collected using the survey procedure. There are many different tools used in the survey techniques for collecting the data from the respondents however the current study used the selfadministered questionnaire for collecting data.

\section{Instrument of the study}

The questionnaire of the study is designed to collect data for all the main and mediating variables for the study. The questionnaire of the study consist of five main parts, all the questions in the questionnaire were marked at a five point likert scale where 1 stands for complete disagreement and 5 stands for complete agreement with the statements. The items used in the questionnaire are adopted from Musiime \& Ramadhan (2007) where the items were used for collecting data related to the impacts of online banking CRM on the level of satisfaction and retention.

The first part of the questionnaire is optional and collect bio data of the participants upon their discretion. The second part consists of 5 different statements designed to extract perception of the online CRM of standard chartered bank of Pakistan, 15 different questions were designed to collect data for Perceived value, perceived cost and perceived switching cost for the customers. Third and fourth part consists of 20 questions designed to collect data for customer satisfaction and customer retention.

\section{Reliability and Validity}

This research attempted to ensure both reliability and validity. For the sake of validity, each variable was measured through multiple questionnaire items having various perspectives. For ensuring reliability, a pre-questionnaire pilot study was conducted from amongst the respondents working in the bank. The Cronbach consistency alpha values for the online CRM is 0.90, for the Satisfaction variable is 0.91 while for the retention scale items, the alpha value is 0.89 . This suggests that the reliability of the questions is ensured and implies that the questions are reliable and the responses to the question are mostly in congruence with each other.

\section{Regression Models}

\section{Online CRM and Customer Satisfaction}

\section{Path 1: Relationship of Online CRM services with the level of satisfaction of the customers}

A simple regression model was used to analyze the association of online CRM banking services to that of customer's satisfaction of the bank. Involving a set of dependent and independent variables, the regression model for this research can be presented as follow, 


$$
\mathrm{CS}=\alpha+\beta(\mathrm{OCRM})+\varepsilon
$$

Path 2: Relationship of Online CRM Services with Customer Satisfaction through Moderating Variables

$$
\mathrm{CS}=\alpha+\beta 1(\mathrm{OCRM})+\beta 2(\mathrm{PV})+\beta 3(\mathrm{PSC})+\beta 4(\mathrm{PP})
$$

\section{Online CRM and Customer Retention}

The relationship between Online CRM and customer Retention also follows two paths as presented below.

Path: 1: Relationship of Online CRM services with the retention of the customers

To analyze the relationship of the online services of the bank with the level of retention of customers of the bank, the study uses a simple regression model. The regression model for the relationship of the dependent and independent variable of the study can be presented as follow,

$$
\mathrm{CR}=\alpha+\beta(\mathrm{OCRM})+\varepsilon
$$

Path: 2: Relationship of Online CRM and Customer Retention through Job Satisfaction

The second Path for the relationship between Online CRM and customer Retention is through the role of Customer satisfaction and is presented as follow,

$$
\mathrm{CR}=\alpha+\beta 1(\mathrm{OCRM})+\beta 2 \mathrm{M}
$$

Where $\beta 2$ stands for the impacts of OCRM and customer Satisfaction of customer retention.

\section{Results and Discussion}

\section{Impacts of OCRM on customer satisfaction}

In order to analyze the relationship of OCRM and customer satisfaction two paths were used the first path shows the direct impacts of Online CRM on customer level of satisfaction. The second path shows the relationship of OCRM and CS with the impacts of mediating variable used in the analysis.

\section{Impacts of OCRM on CS Path 1}

\begin{tabular}{|lllll|}
\multicolumn{5}{c|}{ Table 1 Impacts of OCRM on CS Path 1 } \\
\hline Constant & B & Beta & Std..Error & T value \\
Online CRM & .301 & & .095 & $3.164^{* * *}$ \\
F & .925 & .971 & .030 & $30.845^{* * *}$ \\
R & $51.4^{* * *}$ & & & \\
R square & .97 & & & \\
\hline
\end{tabular}

Dependent Variable: Customer Satisfaction

$*, * *$ and $* * *$ presents significance at $10 \%, 5 \%$ and $1 \%$ respectively

Table 1 of the study presents the coefficients for the relationship of OCRM and CS for the online banking customers of Standard chartered bank. In the table value for R is .97 which shows that CS and OCRM have a positive covariance and both of these variables move in the same direction. The value of $R$ states that 
there is a strong positive covariance among CS and OCRM. The value for R square is .94 which states that almost $94 \%$ of the variation in CS is explained by the online CRM for the online banking customer of standard chartered bank in Pakistan.

The $\mathrm{F}$ value in the table is 51.4 which are greater than the value required for the significance of the model. This leads to the acceptance of the model and suggest that the regression model used in the analysis is accurately predicting the relationship between CS and OCRM.

In the table the value for Intercept is .30 which presents the CS level in the respondents without the impacts of OCRM. The $\mathrm{T}$ value for this coefficient is 3.16 that are higher than the critical level required and which suggest that the model has a true intercept.

The value for the slope coefficient of the relationship between CS and OCRM is .92 suggesting that there is a direct relationship between CS and OCRM, an increase in the level of OCRM will have positive influence the CS. a unit increase in OCRM will result in an increase of .92 times in the level of satisfaction of the customers. The $\mathrm{P}$ value is .000 which leads to the acceptance of the alternate hypothesis that there is a positive relationship between the CS and OCRM without the influence of the mediating variables.

\section{Impacts of OCRM on CS through Mediating Variables Path 2}

Table 2 of the study presents Path 2 for the relationship of OCRM and CS with the influence of mediating variables in the analysis. In the table value for $\mathrm{R}$ is .83 which shows that CS and OCRM have a positive covariance under the influence of mediating variables and both of these variables move in the same direction as shown by path 1 for the relationship. The value of $\mathrm{R}$ states that there is a strong positive covariance among CS and OCRM under the influence of mediating variables. The value for R square is .76 which states that almost $76 \%$ of the variation in CS is explained by the online CRM and mediating variables for the online banking customer of standard chartered bank in Pakistan.

Table 2: Impacts of OCRM \& Mediating Variables on CS Path 2

\begin{tabular}{|lllll|}
\hline & B & Beta & Sts.Error & T value \\
Constant & .006 & & .003 & $1.819^{*}$ \\
Online CRM & .994 & 1.043 & .004 & $2.395^{* *}$ \\
Perceived Value & .003 & .004 & .002 & 1.238 \\
Perceived Price & -.987 & -1.307 & .006 & $-7.455^{* * *}$ \\
Perceived Switching Cost & .989 & 1.258 & .006 & $8.352^{* * *}$ \\
F & $41.4 * * *$ & & & \\
R & .83 & & & \\
R square & .76 & & & \\
\hline
\end{tabular}

Dependent Variable: Customer Satisfaction

$*, * *$ and $* * *$ presents significance at $10 \%, 5 \%$ and $1 \%$ respectively.

The $\mathrm{F}$ value in the table is 41.4 which are greater than the value required for the significance of the model. This leads to the acceptance of the model and suggest that the regression model used in the analysis is accurately predicting the relationship between CS mediating variables and OCRM. In the table the value for Intercept is .006 which presents the CS level in the respondents without the impacts of OCRM. The T value for this coefficient is 1.819 that is higher than the critical level required and which suggest that the model has a true intercept. 
The value for the slope coefficient of the relationship between CS and OCRM is .99 suggesting that there is a direct relationship between CS and OCRM, an increase in the level of OCRM will have positive influence the CS. A unit increase in OCRM will result in an increase of .99 times in the level of satisfaction of the customers. The $\mathrm{P}$ values which states the significance is .000 and which tempts the researcher to accept alternate hypothesis that there exists a positive association between the CS and OCRM without the influence of the mediating variables.

The value for the slope coefficient of the relationship between CS and PV is .003 suggesting that there is a direct relationship between CS and PV, an increase in the level of PV will have positive influence the CS. A unit increase in PV will result in an increase of .99 times in the level of satisfaction of the customers. However the $\mathrm{P}$ value for this coefficient is .221 and is insignificant. This leads to the acceptance of the null hypothesis that there is no relationship between the CS and PV.

The value for the slope coefficient of the relationship between CS and PP is -.987 suggesting that there is an inverse relationship between CS and PP, an increase in the level of PP will have negative influence the CS. A unit increase in PV will result in a decrease of -.987 times in the level of satisfaction of the customers. However the $\mathrm{P}$ value for this coefficient is .000 and is significant. This leads to the acceptance of the alternate hypothesis that there is an inverse relationship between the CS and PP.

The value for the slope coefficient of the relationship between CS and PSC is .989 suggesting that there is a direct relationship between CS and PSC, an increase in the level of PSC will have positive influence the CS. A unit increase in PSC will result in an increase of .98 times in the level of satisfaction of the customers. However the $\mathrm{P}$ value for this coefficient is .000 and is significant. This leads to the acceptance of the alternate hypothesis that there is a positive relationship between the CS and PV.

\section{Impacts of Online CRM and Customer Retention}

The relationship of OCRM and customer retention is also analyzed using the simple and multiple regression models. The relationship between OCRM and CR is analyzed using two paths. The direct impact of OCRM on customer retention is analyzed and also the effect of OCRM through customer satisfaction is also analyzed.

\section{Impacts of OCRM on CR Path 1}

Table 3: Path 1: Impacts of OCRM on CR Path 1

\begin{tabular}{|lllll|}
\hline & B & Beta & Sts.Error & T value \\
Constant & .168 & & .061 & $2.736^{* *}$ \\
Online CRM & .965 & .988 & .016 & $60.440^{* * *}$ \\
$\mathrm{~F}$ & $36.9^{* * *}$ & & & \\
$\mathrm{R}$ & .98 & & & \\
$\mathrm{R}$ square & .97 & & & \\
\hline
\end{tabular}

Dependent Variable: Customer Retention

$*, * *$ and $* * *$ presents significance at $10 \%, 5 \%$ and $1 \%$ respectively

Table 3 presents the results of simple regression model showing the relationship between customer's retention and online CRM. In the table value for $\mathrm{R}$ is .98 which shows that CR and OCRM have a positive covariance and both of these variables move in the same direction. The value of $\mathrm{R}$ states that there is a strong positive covariance among CR and OCRM. The value for R square is .97 which states that almost 97\% of the variation in CR is explained by the online CRM for the online banking customer of standard chartered bank in Pakistan. 
The $\mathrm{F}$ value in the table is 36.9 which are greater than the value required for the significance of the model. This leads to the acceptance of the model and suggest that the regression model used in the analysis is accurately predicting the relationship between CR and OCRM.

In the table the value for Intercept is .168 which presents the CR level in the respondents without the impacts of OCRM. The T value for this coefficient is 2.736 that are higher than the critical level required and which suggest that the model has a true intercept.

The value for the slope coefficient of the relationship between CR and OCRM is .96 suggesting that there is a direct relationship between CR and OCRM, an increase in the level of OCRM will have positive influence the CR. A unit increase in OCRM will result in an increase of .92 times in the level of satisfaction of the customers. The $\mathrm{P}$ value is .000 which leads to the acceptance of the alternate hypothesis that there is a positive relationship between the CR and OCRM without the influence of the mediating variables.

\section{Impacts of OCRM on Customer retention through Mediating Variable Path 2}

Table 4 of the study presents Path 2 for the relationship of OCRM and CR with the influence of mediating variables in the analysis. In the table value for $\mathrm{R}$ is .98 which shows that CR and OCRM have a positive covariance under the influence of mediating variables and both of these variables move in the same direction as shown by path 1 for the relationship. The value of $\mathrm{R}$ states that there is a strong positive covariance among CR and OCRM under the influence of mediating variables. The value for R square is .96 which states that almost $96 \%$ of the variation in CR is explained by the online CRM and mediating variables for the online banking customer of standard chartered bank in Pakistan.

The $\mathrm{F}$ value in the table is 68.2 which are greater than the value required for the significance of the model. This leads to the acceptance of the model and suggest that the regression model used in the analysis is accurately predicting the relationship between CR mediating variables and OCRM.

Table 4: Path 2: Impacts of OCRM on CR with Mediating Effects Path 2

\begin{tabular}{|lllll|}
\hline & $\mathrm{B}$ & Beta & Std.Error & T value \\
Constant & .211 & & .094 & $2.255^{* *}$ \\
Customer Satisfaction (x) & 1.549 & 1.440 & .119 & $12.978^{* * *}$ \\
Online CRM & .493 & .481 & .114 & $4.337 * * *$ \\
F & $68.2 * * *$ & & & \\
R & .98 & & & \\
R Square & .96 & & & \\
\hline
\end{tabular}

Dependent Variable: Customer Retention

$*, * *$ and $* * *$ presents significance at $10 \%, 5 \%$ and $1 \%$ respectively

In the table the value for Intercept is .211 which presents the CR level in the respondents without the impacts of OCRM. The T value for this coefficient is 2.255 that is higher than the critical level required and which suggest that the model has a true intercept.

The value for the slope coefficient of the relationship between CR and CS is 1.5 suggesting that there is a direct relationship between CS and CR, an increase in the level of CS will have positive influence the CR. A unit increase in CS will result in an increase of 1.5 times in the level of satisfaction of the customers. The $P$ values which states the significance is .000 and leads to the acceptance of the alternate hypothesis that there is a positive relationship between the CS and CR. The value for the slope coefficient of the relationship between CR and OCRM is .493 suggesting that there is a direct relationship between CS and $\mathrm{CR}$, an increase in the level of CS will have positive influence the CR. A unit increase in OCRM will result in an increase of .493 times in the level of satisfaction of the customers. The $\mathrm{P}$ values which states the 
significance is .000 and leads to the acceptance of the alternate hypothesis that there is a positive relationship between the CR and OCRM.

\section{Main Findings}

The study analyzed the relationship of customer retention and satisfaction with online CRM for the standard chartered bank of Pakistan. The main findings of the study are given below,

- The regression analysis suggest that online CRM is a strong determinant of the customer satisfaction and customer retention as perceived by the online banking customers for standard chartered bank Pakistan. The analysis suggests that OCRM explains a great deal of variation in the level of customer satisfaction and customer retention.

- The results for Path 1 of the relationship between OCRM and CS suggest that there are direct impacts of OCRM on CS suggesting that an increase in the level of OCRM will have positive impacts on the level of CS.

- The results with mediating variable that is Path 2 of the analysis also supports the point that there is a positive relationship between OCRM and CS through the impacts of OCRM on customer perceived value, perceived cost and perceived switching costs.

- OCRM is also found to have positive impacts on the level of loyalty of the customers through Path 1 which shows direct impacts of OCRM on CR. An increase in the level of OCRM will increase the level of customer loyalty and hence reduces the chances of customer switching over.

- The impacts of OCRM on CR through the mediating effects of customer satisfaction also supports the results of Path 1 and suggest that the An Increase in OCRM leads to an increase satisfaction for the customers and that in turn results in an increased level of customer retention for standard chartered bank Pakistan.

\section{Conclusion}

Online banking approach is one of the most widely used tools for keeping in touch with the customers and thereby maintains a competitive edge over the rivals in the industry. This trend has increased manifold only after the current pandemic where people are reluctant to visit banks in person. Customer relationship management through online banking services and products has helped banks to personalize their relationship with customers, has increased responsiveness, ease of information and transaction to the customers.

In the Covid-19 pandemic scenario, CRM stands vital for sustaining the complex relation of the company with their customers that is triggered at providing personal, authentic and customized services to the customers and retaining these customers through continous improvements. The use of Information technology has presented new horizons for the CRM and possess great potentioal for gaining a competetive edge for the company in markets. CRM through online banking products and services is widely pursued by the Pakistani banking industry and some important players in the industry have already gained significant implication of the technique used. This study investigated the impacts of online CRM on the level of customer satisfaction and the retention of the customers in the Pakistani Banking industry. The reserch distributed the questionnaire of the study which was returned filled in by 100 respondents. Data collected for the variables was then analyzed using the regression analysis techniques.

Online CRM is a very strong determinant of the customer satisfaction and customer retention as perceived by the online banking customers for standard chartered bank Pakistan. There are direct impacts of OCRM on CS suggesting that an increase in the level of OCRM will enhance level of customer satisfaction. This impact is valid through direct effects of OCRM and its affects through the Perceived value, price and switching cost. OCRM have positive impacts on the level of loyalty of the customers through its direct 
impacts of OCRM on CR. An increase in the level of OCRM will increase the level of customer loyalty and hence reduces the chances of customer switching over. Increase in OCRM leads to an increased satisfaction for the customers and that in turn results in an increased level of customer retention for standard chartered bank Pakistan. The overall results from the analysis are in line with the results of previous studies and validate the point that online CRM is a vital competency for banks through which they can distinguish their position in the banking industry.

\section{Limitations and Recommendations}

The study analyzed the relationship between customer retention and the CRM policy of the banks operating in KPK. The emerging nature of the Pakistani economy and the demographic conditions of the customers in the sample presents some limitation to the generalization of the results of the study. The data collected presents the perceptions of the customers and the indicators of satisfaction and retention are not in absolute terms. The implication of the study also needs to be reconciled with the technological attributes of the online CRM service provider's bank as banks may differ based on their quality of CRM services. For instance, while this study was based on only Standard Chartered Bank as Case analysis, generalizations to other commercial banks should not be made blindly, as there are differences in technological sophistication and CRM services.

Results of study suggest that customer relationship management is a key to success in the current market scenario. The online banking is playing a key role in enhancing the outcomes of the CRM. Some recommendations which can help banks achieve their goals with the CRM strategy.

- Banks need to recognize the importance of Customer relationship management and along with this they also need to stay up to date with the technological advancements. Use of Innovative tools and techniques along with personalized contacts with the customers of the company can help company to retain customers from turning over to the rivals.

- Online CRM can be used as a valuable and attractive platform for positioning the new offering of the banks to its customers. The customers retained through Online CRM have high probability of availing the new offerings of the bank.

- Features, responsiveness, reliability and the switching costs of the Online CRM for the customers are key elements in the strategy of Online CRM which can enhance the effectiveness of the strategy.

\section{Contribution and Future Reserach Directions}

The online banking CRM is initiated for enhancing the level of customer satisfaction and to retain the existing customers of the bank. The policy makers and the management in the banks are interested in knowing the impacts of the Online CRM on the level of satisfaction and the retention of the customers. The results of the study add some new knowledge to the existing findings available on the issue and provide some new insights for the implication of Online Customer relationship management. The findings provide important tools for the enhancing the level of customer satisfaction and retention.

Future research needs to analyze the elements of the CRM strategy and their relative contribution and integration into organizational strategy to make it sustainable in a post-pandemic era. The quality of the Online CRM strategy and its determinants hold an important aspect for future research as the companies are narrowing on services provided through CRM. In addition, future research should also undertake similar empirical analysis in other commercial banks of the country and then contrast the findings with neighboring countries to make meaningful progress in the banking industry. 


\section{References}

Baker, S. (2003). New consumer marketing: Managing a living demand system. England: Wiley.

Bilal, A, (2008). Determinants of customer loyalty and proposing a customer loyalty model for the banking sector of pakistan. Annual Reserach Journal Comsate Institute of Information Technology Abbottabad, Pakistan, 4, 124-139.

Brown, S. A., \& Gulycz, M. (2002). Performance Driven CRM: How to make your customer relationship management visions a reality. Ontario: John Wiley

Buckinx, W., Verstraeten, G. \& Poel, D. Van den, (2007). Predicting customer loyalty using the internal transactional database. Expert Systems with Applications, 32(1), 125-134

Boozy, R. P. (2009). Marketing as an Organized Behavioral System of Exchange. Journal of Marketing, 38 (4), 77-81.

Cronin, M.J. (2009). Banking and finance on the Internet. Van Nostran Reinhold. New York.

Chan, S., \& Lam, J. (2009). Customer Relationship Management on Internet and Mobile Channels: An Analytical Framework and Research Directions. Idea Group Inc.

Dabholkar, P. \& Bagozzi, R.P. (2002). An attitudinal model of technology-based self-service: moderating effects of consumer traits and situational factors. Journal of the Academy of Marketing Science, Summer, 30(2), 184-202

Deakin, M., Goddard, C. \& Welch, B. (2008). Electronic banking: background and history. Electronic banking and treasury security. International Treasury Management Series.3 (4)

Dowling, G. (2002). Customer Relationship Management: In B2C Markets, Often Less Is More. California Management Review, 44(3), 121-137

Engler, H. \& Essinger, J. (2010). The future of banking. Reuters-Pearson Education. London.

Essinger, J. (2008). The virtual banking revolution; the customer, the bank and the future. International Thomson Business Press.

Gao, P., \& Owolabi, O. (2008). Consumer adoption of internet banking in Nigeria. International Journal of Electronic Finance, 2(3), 284-299.

Gil,Ben-Dov (2011). "Customers are expecting you to know them better". http://www.market2lead.com

Harnish, Michael \& Casari,Tricia.(2008). Are we there yet? "The ongoing Evolution of customer`s Relationship Management". Indian Journal of Marketing, 1, 44-72.

Holland, C.P., \& Westwood, J.B. (2010). Product-market and technology strategies in banking. Communications of the association for computing machinery. New York Journal of Marketing Management, 6, 53-57

Joshu, A.J.\& Moli,P.Koshi. (2008). Expectations \& Perception of service Quality in old \& New Generation banks-A Study of select banks in the south Canara Region. Indian Journal of Marketing, 6-11.

Khaligh, A. A., Miremadi, A., \& Aminilari, M. (2012). The impact of eCRM on loyalty and retention of customers in Iranian telecommunication sector. International Journal of Business and Management, 7(2), 150.

Khan SK (2007). Adoption Issues of Internet Banking in Pakistani Firms. Lulea University of Technology, Sweden. Epubl.ltu.se/1653-0187/2007/009/LTU-PB-EX-07009-SE.pdf

Kelley, L. L., Gilbert, D., \& Mannicom, R. (2005). How e-CRM can enhance customer loyalty. Marketing Intelligence \& Planning.

Li, C. T., \& Wu, W. L. (2007). Customer retention and cross buying. Journal of Financial Services Marketing, 12(2), 132-145.

Lipis, A.H., Marschall, T.R., \& Linker, J.H. (2008). Electronic Banking. Electronic Banking, Inc. Atlanta, Georgia. John Wiley \& Sons Inc.

Lee,Dick.(2011). CRM Success in Financial Institutions. Don't Bank on it-yet.http://crmguru.custhelp.com

Mbama, C. I., \& Ezepue, P. O. (2018). Digital banking, customer experience and bank financial performance. International Journal of Bank Marketing, 36(2), 230-255.

Mohsan, F., Nawaz, M. M., Khan, M. S., Shaukat, Z., \& Aslam, N. (2011). Impact of Customer Satisfaction on Customer Loyalty and Intentions to Switch: Evidence from Banking Sector of Pakistan. International Journal of Business and Social Science, 2(16), 230-245 
Michaels, J.W. (2008). PC banking household segments. Forbes, 12, 261-262

Moscove, S.A., Simkin, M.G., \& Bagranoff, N.A. (2008). Core concepts of accounting information system. John Wiley \& Sons Inc. (6)

Musiime, A., \& Ramadhan, M. (2011). Internet banking, consumer adoption and customer satisfaction. African Journal of marketing management, 3(10), 261-269.

Ombati, T. O., Magutu, P. O., \& Nyamwange, S. O. (2010). Technology and service quality in the banking industry. African Journal of Business \& Management, 1.

Parker, K. R., Nitse, P. S., \& Tay, A. S. (2009). The impact of inaccurate color on customer retention and CRM. Informing Science: The International Journal of an Emerging Transdiscipline, 12, 105-121.

Rigby, D. K., Reichheld, F., \& Dawson, C. (2003). Winning customer loyalty is the key to a winning CRM strategy. Ivey business journal, 67(4), 1.

Ratten, V. (2020). Coronavirus (Covid-19) and entrepreneurship: cultural, lifestyle and societal changes. Journal of Entrepreneurship in Emerging Economies, In Print, Sept 2020

Romm, C.T. \& Sudweeks, F. (2008). Doing business electronically, a global perspective of electronic commerce. Springer-Verlag. London.

Ramakrishnan, K. (2006). Customer retention: the key to business performance (online).Available:http://www.estrategicmarketing.com/smNovDec2/art11.html(Accessed:1November 2015)

Saha P, Zhao Y (2005). Relationship between online service quality and customer satisfaction. A case of Internet banking. International Banking Review, 26(13)

Smith, L.M., Strawser, R.H., Wiggins Jr, C.E. (2008). Readings and problems in accounting information system. Mcgraw-Hill Companies Inc.

Sharma, Ashvine Kumar \& Nagpal,Shafali. (2011). Marketing Customer Information File (MCIF): A Powerful Tool For Banks. Indian Journal of Marketing, 36(3), 27-30.

Taylor, P.C. (2008). Big trends in community banking for 2010. America's Community Banker, 3, 16-19

Uppal, R. K., \& Kaur, R. (2007). Quality of Services in E-Banks and Traditional Banks: An Empirical Study of Employee's Perceptions In India. The IUP Journal of Management Research, 6(2), 26-35.

Williams, B.C., \& Spaul, B.J. (2008). I.T. and accounting; the impact of information technology. The Chapman \& Hall Series in Accounting and Finance.

Wong, C. B. (2011). Perceptions of Customer Satisfaction, Switching Costs and Customer Retention: An Empirical Study of Basic and Advanced Internet Banking Users in Hong Kong. Global Journal of Management And Business Research, 11(2). 